\title{
Loss of Rab25 promotes the development of intestinal neoplasia in mice and is associated with human colorectal adenocarcinomas
}

\author{
Ki Taek Nam,1,2 Hyuk-Joon Lee,,2,3 J. Joshua Smith,2,4 Lynne A. Lapierre, ${ }^{2}$ Vidya P. Kamath, ${ }^{5}$ \\ Xi Chen, ${ }^{6}$ Bruce J. Aronow, ${ }^{7}$ Timothy J. Yeatman, ${ }^{5}$ Sheela G. Bhartur, ${ }^{8}$ Benjamin C. Calhoun, ${ }^{8}$ \\ Brian Condie, ${ }^{8,9}$ Nancy R. Manley, ${ }^{8,9}$ R. Daniel Beauchamp, ${ }^{2,4}$ \\ Robert J. Coffey, 1,4,10 and James R. Goldenring ${ }^{1,2,4,8}$
}

\begin{abstract}
${ }^{1}$ Nashville Department of Veterans Affairs Medical Center and 2Department of Surgery, Vanderbilt University School of Medicine, Nashville, Tennessee. ${ }^{3}$ Department of Surgery and Cancer Research Institute, Seoul National University College of Medicine, South Korea. ${ }^{4}$ Department of Cell and Developmental Biology, Vanderbilt University School of Medicine. ${ }^{5} \mathrm{H}$. Lee Moffitt Cancer Center and Research Institute, Tampa, Florida. ${ }^{6}$ Division of Cancer Biostatistics, Vanderbilt University School of Medicine. ${ }^{7}$ Cincinnati Children's Hospital Medical Center and University of Cincinnati School of Medicine, Ohio. ${ }^{8}$ Institute of Molecular Medicine and Genetics, Medical College of Georgia, Augusta. ${ }^{9}$ Department of Genetics, University of Georgia, Athens. ${ }^{10}$ Department of Medicine, Vanderbilt University School of Medicine.
\end{abstract}

\begin{abstract}
Transformation of epithelial cells is associated with loss of cell polarity, which includes alterations in cell morphology as well as changes in the complement of plasma membrane proteins. Rab proteins regulate polarized trafficking to the cell membrane and therefore represent potential regulators of this neoplastic transition. Here we have demonstrated a tumor suppressor function for Rab25 in intestinal neoplasia in both mice and humans. Human colorectal adenocarcinomas exhibited reductions in Rab25 expression independent of stage, with lower Rab25 expression levels correlating with substantially shorter patient survival. In wild-type mice, Rab25 was strongly expressed in cells luminal to the proliferating cells of intestinal crypts. While Rab25-deficient mice did not exhibit gross pathology, $\mathrm{Apc}^{\mathrm{Min} /+}$ mice crossed onto a Rab25-deficient background showed a 4-fold increase in intestinal polyps and a 2 -fold increase in colonic tumors compared with parental $\mathrm{Apc} \mathrm{Min} /+^{+}$ mice. Rab25-deficient mice had decreased $\beta_{1}$ integrin staining in the lateral membranes of villus cells, and this pattern was accentuated in Rab25-deficient mice crossed onto the $\mathrm{Apc}^{\mathrm{Min} /+}$ background. Additionally, $\mathrm{Smad3}^{+/-}$ mice crossed onto a Rab25-deficient background demonstrated a marked increase in colonic tumor formation. Taken together, these results suggest that Rab25 may function as a tumor suppressor in intestinal epithelial cells through regulation of protein trafficking to the cell surface.
\end{abstract}

\section{Introduction}

Alterations in membrane-trafficking patterns can radically affect the maintenance of polarity in differentiated epithelial cells, and a loss of polarity is thought to play a critical role in the early pathogenesis of neoplasia $(1,2)$. Rab small GTPases are involved in the full gamut of vesicle-trafficking pathways within cells $(3,4)$. In particular, the Rab11 family members, consisting of Rab11a, Rab11b, and Rab25, regulate various aspects of membrane recycling and trafficking to the plasma membrane $(5,6)$. Rab25 is enriched in epithelial cells (5). Prominent expression of Rab25 has been observed throughout the gastrointestinal mucosa, with the highest expression seen in ileum and colon. High levels of expression are also present in the lung and kidney, with a very minor and variable level of expression in splenic tissue. No expression of Rab25 has been seen in the brain, heart, liver, skeletal muscle, or the gastric wall (5). Recent investigations have suggested that Rab25 expression can alter breast and ovarian tumor cell-line behavior. Cheng et al. (7) noted that MCF-7 breast carcinoma cells exhibited more aggressive properties following overexpression of Rab25. In contrast, Rao and colleagues (8) have suggested that loss of Rab25 in breast cancer cell lines lacking estrogen and progesterone receptors leads to more aggressive behavior. It seems likely

Conflict of interest: The authors have declared that no conflict of interest exists. Citation for this article: J Clin Invest. 2010;120(3):840-849. doi:10.1172/JCI40728. that some of these divergent findings may result from regulation of pathways dictating the trafficking of specific cargoes. Recent studies have indicated that, in an ovarian cancer cell line, Rab25 associates with and regulates the trafficking of $\alpha_{5} \beta_{1}$ integrin and that this can alter tumor cell invasion in vitro (9).

Current models for colorectal adenocarcinoma implicate serial genetic alterations within the colonic epithelium as the basis of cancer formation. Based on its genetic origin, colon cancer can be divided into 2 classes, polyposis colon cancer and nonpolyposis colon cancer. Genes whose mutations are responsible for colon carcinogenesis have been discovered through molecular genetic studies of hereditary cancer predisposition syndromes such as familial adenomatous polyposis (FAP) and hereditary nonpolyposis colorectal cancer (HNPCC) $(10,11)$. Individuals with FAP develop numerous benign colorectal polyps due to a germline mutation in the adenomatous polyposis coli (APC) gene, which was identified on chromosome $5 \mathrm{q}$ as one of the genes commonly deleted in FAP kindreds (12, 13). The first mouse mutant in the Apc gene (the mouse homolog of human APC on mouse chromosome 18) was identified from a colony of randomly mutagenized mice (14). This mutant, multiple intestinal neoplasia (Min) carried a truncation mutation at codon 850 of the Apc gene; hence the designation of $A p c^{\text {Min }}$ (15). All Apc mutant mice develop adenomatous polyps in the small intestine and with lower frequency also in the colon, but tumors rarely progress to adenocarcinoma. If additional mutations are introduced 

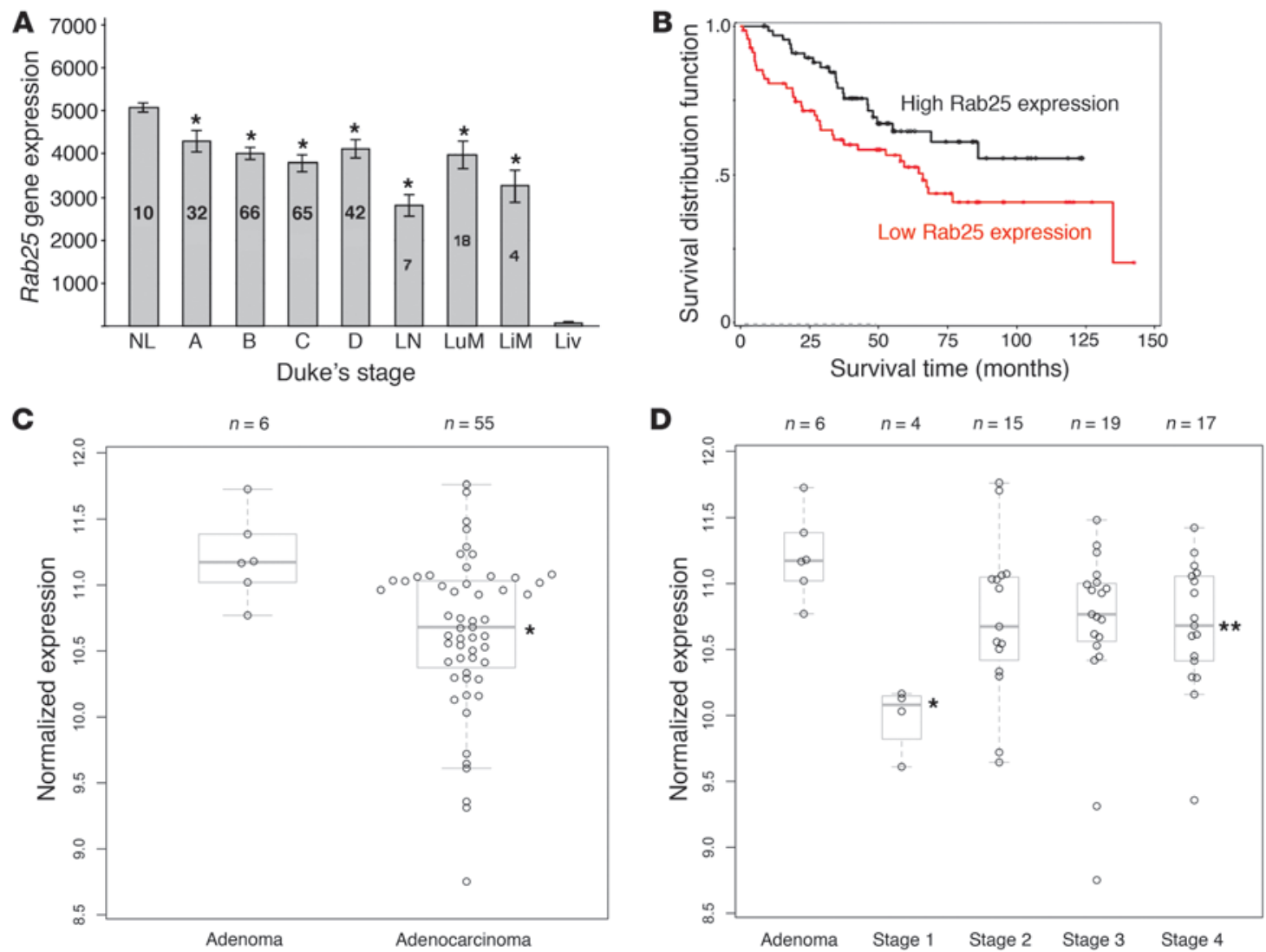

Figure 1

Rab25 gene expression and human colon cancer. (A) Rab25 expression in a cohort of colon cancer patients and controls with extensive gene microarray expression profiling. Gene expression was assessed for Rab25 using the Affymetrix 218186 probe set (numbers in bars indicate patient numbers). Expression of Rab25 was significantly decreased in colon adenocarcinomas compared with normal colon (NL) $\left({ }^{*} P<0.03\right)$ independent of Duke's stage. Rab25 expression was also reduced in LN metastases as well as in liver (LiM) and lung (LuM) metastases. All values are shown as mean \pm SEM. (B) Comparison of overall survival in colon cancer patient data for gene Rab25. Kaplan-Meier analysis was performed comparing patients with Rab25 expression above the median (high Rab25 expression) or with Rab25 expression below the median (low Rab25 expression). Lower expression of Rab25 correlated with significantly lower survival $(P<0.035)$. (C) Normalized expression for Rab25 in 6 colon adenoma and 55 colon adenocarcinoma samples from Vanderbilt analyzed by microarray. Rab25 expression was significantly decreased in the adenocarcinoma group compared with the adenomas $\left({ }^{*} P=0.02\right)$. All values are shown as mean \pm SEM. (D) Normalized expression data for Rab25 across adenomas and individual AJCC stages (I-IV). Rab25 transcript expression was significantly lower in stage I and stage IV tumor specimens $\left({ }^{\star} P<0.001\right.$ and ${ }^{* *} P=0.02$, respectively) compared with specimens from patients with adenomas. All values are shown as mean \pm SEM.

into these mice, however, these additional genetic events can lead to development of more advanced tumors $(16,17)$. HNPCC is caused by mutations in the genes that encode the enzymatic machinery for mismatch repair (18). One locus that is mutated in HNPCC encodes the type II receptor for TGF- $\beta$ (19). A commonly mutated pathway in colon cancer exhibiting microsatellite instability is the TGF- $\beta$ pathway. The SMAD proteins are downstream effectors of the TGF- $\beta$ signaling pathway. As a progressive model of colon cancer, all of the $\operatorname{Smad}^{-1-}$ mice on the 129/Sv background develop proximal and/or distal colonic tumors by 6 months of age (20).

We have sought to determine the effects of loss of Rab25, an epithelial-specific small GTPase, on the evolution of colonic neoplasia. We have observed that Rab25 expression is significantly lower in human colon cancers independent of stage and lower Rab25 expression predicts poorer survival. In mice, targeted disruption of Rab25 expression promotes intestinal neoplasia in 2 different pathway models of either intestinal polyposis or colon carcinogen- esis. We also have shown that loss of Rab25 in the intestine leads to a reduction in basolateral presentation of $\beta_{1}$ integrin in intestinal villi and correlates with the promotion of polyp formation. Taken together, all of this work supports a role of Rab25 as a tumor suppressor in intestinal mucosae.

\section{Results}

Rab25 gene expression in buman colon cancer. Given the findings in breast cancer specimens, which suggested that Rab25 levels were altered in breast cancer, we interrogated an established database of gene-expression profiles for human colon cancers (21). Gene expression was assessed for Rab25 using the Affymetrix 218186 probe set. Expression of Rab25 was significantly decreased in colon adenocarcinomas compared with normal colon $(P<0.03)$ independent of Duke's stage. Rab25 expression was also reduced in LN metastases as well as in liver and lung metastases (Figure 1A). Moreover, we also compared overall survival in colon cancer 


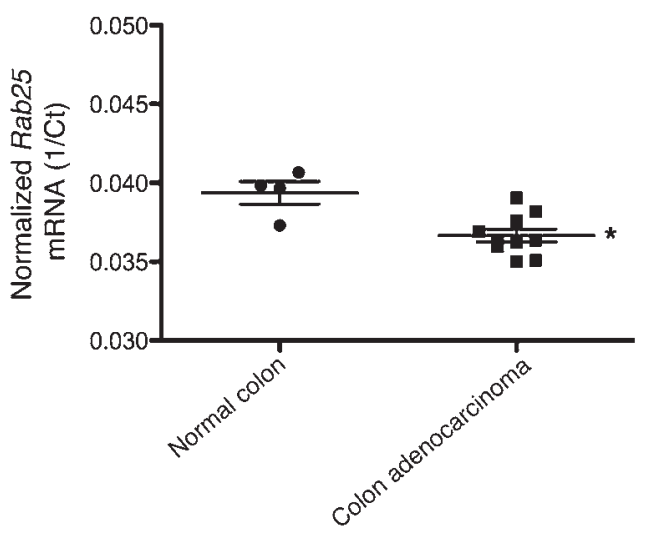

patients according to expression of Rab25. Kaplan-Meier analysis was performed comparing survival in patients with Rab25 expression above the median (low risk) to those with Rab25 expression below the median (high risk). Lower expression of Rab25 correlated with significantly shorter survival $(P<0.035)$ (Figure 1B). These results suggested that Rab25 might act as a tumor suppressor in the colon.

To determine whether Rab25 was differentially expressed in an independent cohort of colorectal cancer patients, we interrogated Affymetrix gene microarray results for expression of Rab25 (probe $218186)$ in patients with adenomas $(n=6)$ and adenocarcinomas $(n=55)$ from Vanderbilt Medical Center (22). The demographics for this group are listed in Supplemental Table 1 (supplemental material available online with this article; doi:10.1172/JCI40728DS1). We found that Rab25 expression was significantly lower in the adenocarcinoma group compared with adenomas (Figure 1C; $P=0.02$ ). Additionally, we evaluated adenomas and individual stage groups and found significant differences in the stage I and stage IV patients when compared with adenomas (Figure 1D; $P<0.001$ and $P=0.02)$ and a trend toward lower expression for the stage II and III patients (Figure 1D; $P=0.07$ and $P=0.06$, respectively).

To verify the results in gene microarray studies, we examined Rab25 expression levels in RNA from 4 normal colon samples from patients with diverticulitis compared with 10 colon adenocarcinoma patient samples by quantitative RT-PCR analysis. The colon adenocarcinoma samples spanned the range of stages, with 3 stage I, 4 stage II, 2 stage III, and 1 stage IV tumor. To quantitate differences, we calculated the efficiency-adjusted Ct values for each normal and tumor sample (see Methods). We observed significantly lower expression of Rab25 in colon tumor samples compared with normal colon samples (Figure 2; $P=0.01$ ). Taken together, these data confirmed that Rab25 expression was significantly decreased in adenocarcinomas and supported a potential tumor-suppressive role for Rab25 in colorectal cancer.

Construction and characteristics of Rab25-knockout mouse. To address directly the effects of reduced Rab25 expression on colonic neoplasia, we constructed a mouse with targeted disruption of the Rab25 gene (Figure 3). Rab25-deficient mice were born in normal Mendelian ratios and did not show any significant abnormalities up to 4 months of age. Mice were bred through 12 generations of crossing to either C57BL/6 or $129 / \mathrm{J}$ strain backgrounds without any alterations in gross phenotype. Rab25-deficient mice did not show any detectable levels of Rab25 mRNA, and in addition, there was a complete absence of detectable Rab25 protein (Figure 3D).

\section{Figure 2}

Rab25 expression is lower in colon cancers compared with normal colonic mucosa. 14 patient samples (4 normal colon samples and 10 colon adenocarcinomas) were examined by quantitative RT-PCR analysis. The 1/Ct adjusted Rab25 expression values were determined for all samples. A significant reduction of Rab25 expression was observed when normal samples were compared with tumor samples $\left({ }^{\star} P=0.01\right.$; Mann-Whitney $U$ test). All values are shown as mean \pm SEM.

Interestingly, we observed that heterozygous mice showed intermediate reductions in Rab25 protein expression, suggesting haploinsufficiency (Figure 3D). C57BL/6 background mice showed no significant anatomical or pathological abnormalities up to 1 year of age. For Rab25-deficient mice on the 129/J background only, after 10 months of age, we observed the development of vaginal cancer in virgin females and distal esophageal stricture due to squamous cell hyperplasia in both males and females (K.T. Nam, unpublished observations).

Rab25 is an epithelial-specific small GTPase (5). Therefore, as a final means to establish the efficacy of the Rab25 knockout, we compared the staining for Rab25 in intestine in wild-type versus Rab25-deficient mice. Figure 3E demonstrates that Rab25 was most strongly expressed in cells on the luminal side of the proliferative zone in intestinal crypts. Rab25 staining localized to the perinuclear region in a pattern similar to that observed previously in Barrett epithelium (23). No staining for Rab25 was observed in the intestines of Rab25-knockout mice (Figure 3E).

The effects of Rab25 deficiency associated with tumor initiation in the $A p c^{\mathrm{Min} /+}$ mice. Apc $c^{\mathrm{Min} / \mathrm{+}}$ mice, which are heterozygous for mutant $A p c$, develop multiple polyps in the small bowel and a smaller number of polyps in the colon (24). To assess the role of Rab25 in regulating tumorigenesis, we examined polyp formation in $A p c^{\mathrm{Min} /+}$ mice bred onto a background of $\mathrm{Rab}_{25^{+/+}}, \mathrm{Rab} 25^{+/-}$, or $\mathrm{Rab} 25^{-/-}$. Figure $4 \mathrm{dem}-$ onstrates that $A p c^{\mathrm{Min} /+} ; \mathrm{Rab} 25^{-/-}$mice showed an increase in tumor formation throughout the intestines. We observed a significant 4-fold increase in tumor number (Figure 4, B and C, and Supplemental Table 2). Interestingly, $A p C^{\mathrm{Min} /+} ; \mathrm{Rab}_{25^{+/-}}$mice also showed a significant increase in tumor number that was intermediate between wild-type and Rab25-deficient mice (Figure 4B and Supplemental Table 2). These studies indicated that Rab25 loss promoted adenoma formation and that the effects correlated with Rab25 dosage.

We also examined the presence of colonic tumors in $\mathrm{ApC}^{\mathrm{Min} / \mathrm{+}}$ mice on the Rab25-deficient or heterozygous backgrounds. Figure 5 demonstrates that $A \mathrm{PC}^{\mathrm{Min} /+} ; \mathrm{Rab} 25^{-/-}$mice showed a significant 2 -fold increase in colonic polyp number as well as a significant increase in polyp size (Figure 5B and Supplemental Table 2). We also observed that polyps were distributed more widely in the colon in $A \mathrm{PC}^{\mathrm{Min} /+}$; Rab25-/- (Figure 5B). The results indicate that Rab25 loss is associated with increased tumor formation in $A p c^{\mathrm{Min} /+}$ mice.

Microscopic examination of the $A p \mathrm{C}^{\mathrm{Min} /{ }^{+}}$mouse tumors in both the intestine and colon showed that the lesions were tubular adenomas, as previously noted in $\mathrm{ApC}^{\mathrm{Min} / \mathrm{+}}$ mice (Figures 4 and 5). We did not observe any increase in invasive character in the adenomas in 
A

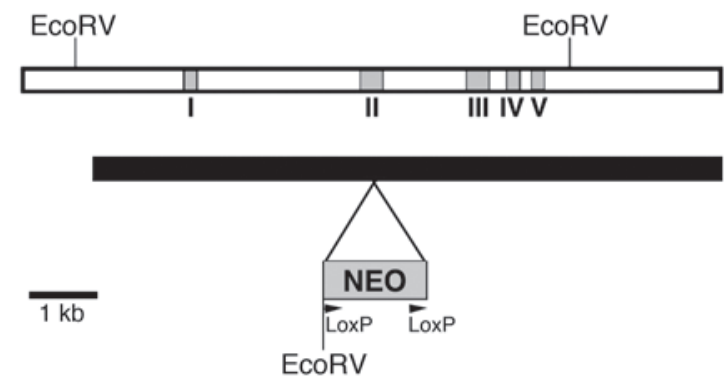

\section{Figure 3}

Construction of Rab25-knockout mouse. (A) Schematic of the targeting construct for disruption of the Rab25 gene with insertion of the neomycin sequence into exon II of the Rab25 gene. The NEO cassette contained termination codons in all 3 frames. (B) Southern blot of EcoRV digests of DNA from heterozygote (+/-), homozygote wild-type (+/+), and 2 Rab25-knockout mice $(-/-)$ probed with sequence from exon $\mathrm{V}$. (C) 3 oligonucleotide PCR-based screening assays showed discrimination of Rab25-knockout mice from heterozygotes and wild-type littermate mice. (D) Western blot of extracts of protein $(50 \mathrm{mg})$ from the gastric mucosa of littermate mice probed with rabbit anti-mouse Rab25 showing reduction of Rab25 expression in heterozygotes and complete absence of detectable Rab25 in Rab25knockout mice. The distribution of molecular mass standards is indicated at left $(\mathrm{kDa})$. The lane images shown are from noncontiguous lanes of the same gel and Western blot. (E) Immunohistochemical localization of Rab25 in the intestinal mucosa of wild-type mice (+/+) using either immunohistochemistry (left 2 panels) or immunofluorescence (third panel; green is Rab25 and blue is DAPI). The cells in the transition zone between the crypt and the villus stained most strongly for Rab25. In Rab25-deficient mice (-/-, far right), no Rab25 staining was observed. Scale bars: $50 \mu \mathrm{m}$.

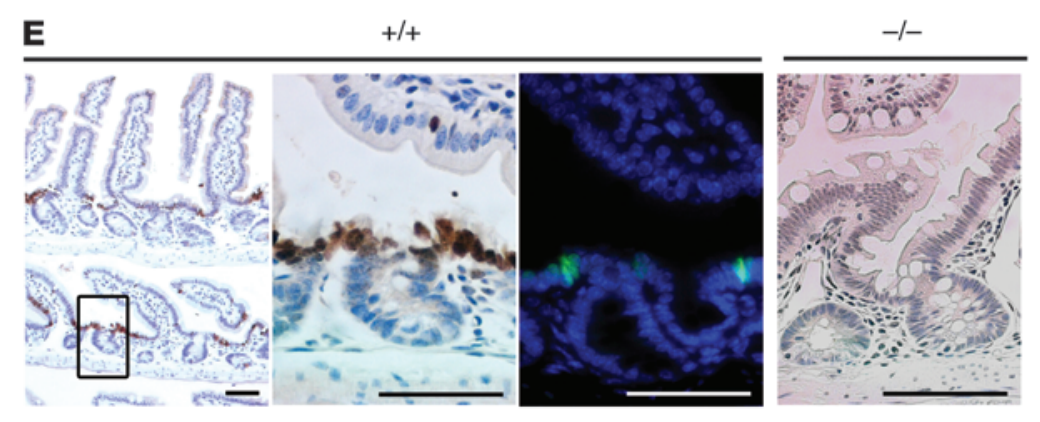

$A p c^{\mathrm{Min} /{ }^{+}} ; \mathrm{Rab} 25^{-/-}$mice. Since adenoma formation in $\mathrm{Ap} \mathrm{C}^{\mathrm{Min} /+}$ mice has been associated with loss of heterozygosity at the wild-type locus $(25,26)$, we have evaluated $A p c$ alleles in microdissected adenomas. We observed no difference in the frequency of loss of heterozygosity

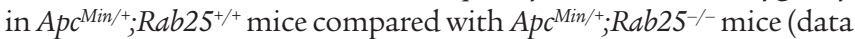
not shown). These results indicate that loss of Rab25 does not alter induction of the loss of heterozygosity at the Apc locus.

We also examined the distribution of Rab25 in $\mathrm{Apc}^{\mathrm{Min} / \mathrm{+}}$ mice. Figure 6 demonstrates that $A p c^{\mathrm{Min} / \mathrm{+}}$ mice with a wild-type Rab25 background showed decreased Rab25 immunostaining in the cells at the transition from crypt to villus (Figure $3 \mathrm{E}$ vs. Figure $6, \mathrm{~A}$ and E). Interestingly, we also observed ectopic expression of Rab25 in villus cells adjacent to intestinal polyps (Figure 6, C and $\mathrm{G})$. Also, we observed no staining for Rab25 in $\mathrm{Apc}^{\mathrm{Min} /+}$ mouse intestinal adenomas and polyps (Figure 6, C and F). As expected, no Rab25 staining was found in $A p c^{\mathrm{Min} /+}$ mice on a Rab25-deficient background (Figure 6, D and $\mathrm{H}$ ).

Rab25 deficiency and $\beta_{1}$ integrin localization in intestinal cells. Previous studies have linked Rab25 to the trafficking of $\beta_{1}$ integrin (9). Therefore, we examined the distribution of $\beta_{1}$ integrin in $\mathrm{Apc} \mathrm{Min} /+^{\mathrm{N}}$ and Rab25-deficient mice (Figure 7). In wild-type mice, $\beta_{1}$ integ- rin staining was prominently observed at the lateral membrane in villus cells, with less staining in crypt cells (Figure 7A). In contrast, villus cells in Rab25-deficient mice had diminished lateral staining with more prominent intracellular staining for $\beta_{1}$ integrin (Figure 7B). In $A p c^{M i n /+}$ mice, we noted a similar decrease in $\beta_{1}$ integrin staining in the lateral membranes of villus cells not immediately associated with adenoma formation as well as in the adenomas themselves (Figure 7, C and E). In $A p C^{\mathrm{Min} /+} ; \mathrm{Rab}^{25^{-/-}}$mice, we observed essentially complete loss of lateral $\beta_{1}$ integrin staining, and staining was only detected intracellularly (Figure 7D). These results suggested that loss of Rab25 affected $\beta_{1}$ integrin localization in intestinal cells.

The effects of Rab25 deficiency associated with tumor invasion in $\mathrm{Smad3}^{+/-}$ mice. Given the striking increase in tumorigenesis observed in $\mathrm{Apc}^{\mathrm{Min} / \mathrm{+}}$ mice on the Rab25-deficient background, we sought to evaluate the effects of Rab25 loss in a second model associated with colon tumor invasion. Loss of Smad3 in mice is associated with development of colon tumors in the proximal colon (20). While Smad3 $3^{-/}$mice develop invasive proximal colon tumors, Smad3 heterozygotes show little if any overt pathology (20). We therefore examined the effects of Rab25 deficiency on the colonic mucosa of 

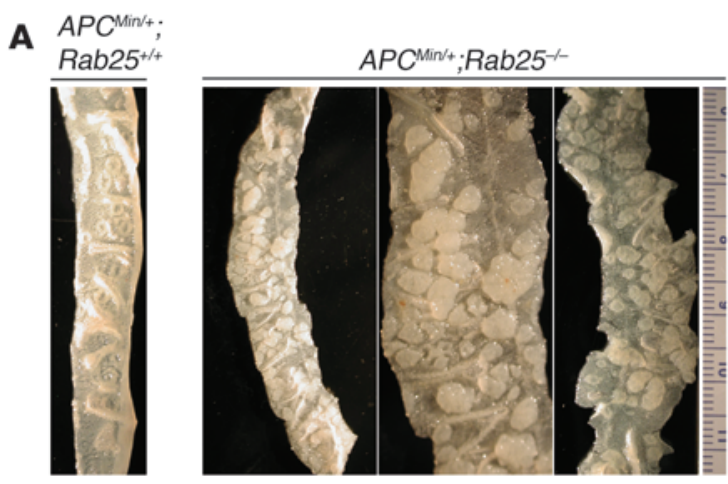

$\mathbf{B}$

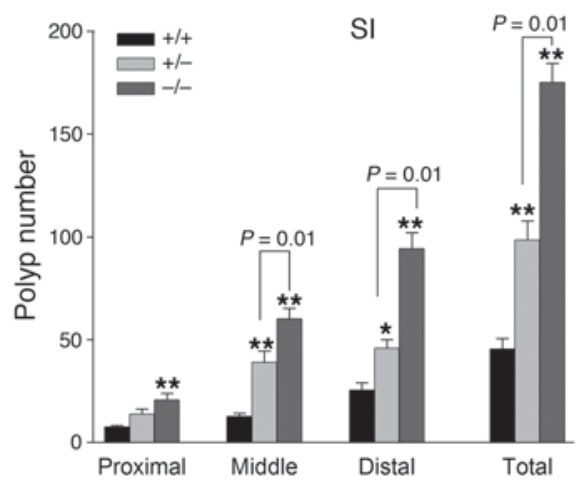

C

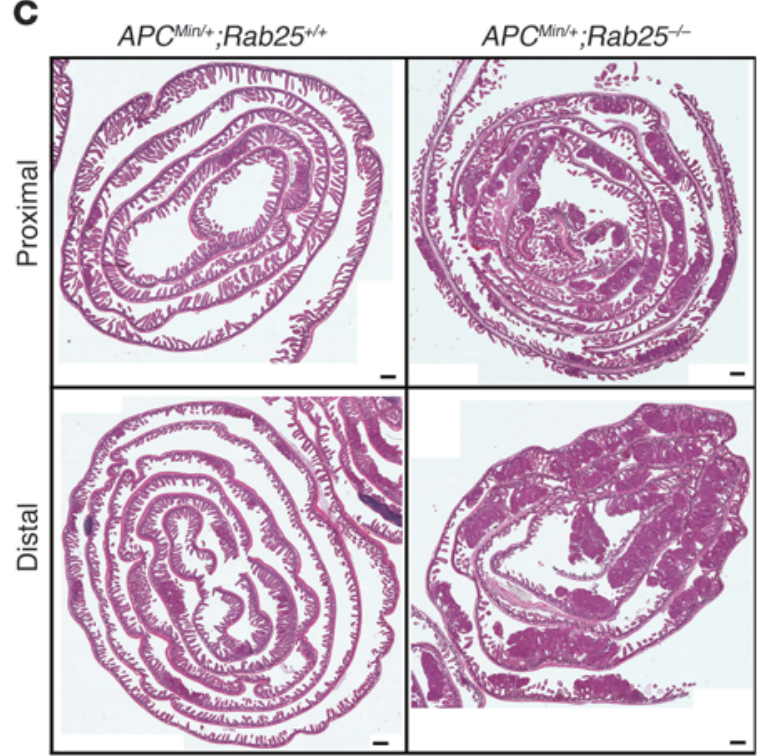

Figure 4

Rab25 deficiency promotes intestinal adenoma formation in Apc Min/+ mice. (A) Gross appearance of small intestine from Apc Min/+;Rab25+/+ (+/+) and $\mathrm{Apc}_{\mathrm{Min} /+} ; \mathrm{Rab}^{25^{-/}}(-/-)$mice. Rab25-deficient mice showed an increase in tumor numbers and size throughout the intestine. (B) Anatomical distribution of polyps in small intestine (SI) of $A p C^{M i n /+} ; R_{a b 25^{+/+}}(+/+)$and $A p C^{M i n /+} ; R_{a b 25^{-/-}(-/-)}$mice. Polyp number was determined in the proximal, middle, and distal intestine as well as in the total intestines of $A p c^{\mathrm{Min} /+} ; R_{a b 25^{+/+}(+/+)}(n=7), A p C^{M i n /+} ; R a b 25^{+/-}(+/-)(n=16)$, and $\mathrm{Apc}^{\mathrm{Min} /+} ; \mathrm{Rab}^{-/-}(-/-)(n=12)$ mice. The distal intestine showed a greater increase in the number of polyps than the proximal intestine. Apc ${ }^{\mathrm{Min} /+}$; Rab25 $5^{+-}$mice also showed a significant increase in tumor numbers that was intermediate between wild-type and Rab25-deficient mice. Data

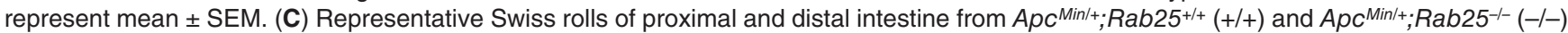
mice. Both proximal and distal intestine from $A p c^{\mathrm{Min} /+;} ; R_{a b 25^{--}(-/-)}$mice showed an increase in tumor number. Scale bars: $1 \mathrm{~mm}$.

$\mathrm{Smad3}^{+/-}$mice. While Smad3 ${ }^{+/-}$mice on a Rab25+/+ background did not show any adenomas (Figure 8, A and B), the $\operatorname{Smad3}^{+/-} ; \mathrm{Rab}_{25} 5^{-/}$ mice showed large invasive lesions in $80 \%$ of animals (Table 1). Tumors were identified in both the proximal colonic mucosa and in the rectum. By microscopic analysis, in $\mathrm{Smad}^{+/-} ; \mathrm{Rab}_{25^{-/}}$mice, a spectrum of tumors was documented that ranged from aberrant or dysplastic crypts, hyperplastic lesions, and adenomatous polyps to cancerous lesions with progressive degrees of atypia and invasion (Table 1). The colonic epithelial tumors often extended into and through the submucosa with neoplastic glands penetrating the muscle wall (Figure 8, C and E, and Table 1). In a typical example of a more aggressive proximal tumor, the glandular atypia resulted in numerous mucin-filled cysts (Figure 8, C, D, F, and G). In Rab25 $5^{-1}$ mice on the 129 background, independent of Smad3, we also observed neoplastic vaginal squamous epithelial cells invading the muscle layer (Figure $8 \mathrm{H}$ ). All of these results support a role for Rab25 loss in the early promotion of colonic neoplasia.

\section{Discussion}

Rab small GTPases have been the focus of considerable investigation over the past decade as critical regulators of intracellular vesicle trafficking. It seems intuitive that membrane trafficking is likely involved in many aspects of cell biology relevant to carcinogenesis, including loss of polarity, cell invasion, and cell metastasis. However, few studies have directly addressed the role of Rab proteins in epithelial neoplasia. Nevertheless, investigations over the past several years have increasingly pointed to roles for Rab proteins and their effectors in the regulation of aspects of the establishment and maintenance of polarity (27). The loss of polarity in epithelial cells represents a critical early event in the pathway toward neoplastic transformation (28). Rab11a, Rab11b, and Rab25 share a number of effectors $(6,29)$. While initial studies had suggested that overexpression of Rab25 potently inhibited trafficking through the apical recycling system (30), it remains unclear whether these results were a direct effect or the result of competition for regulators shared with Rab11a, an established promoter of recycling system trafficking. Indeed, this competition between Rab11a and Rab25 for effectors could be physiologically relevant and regulate the balance between various membrane-trafficking pathways. Imbalances in trafficking could lead to alterations in membrane components that would affect critical aspects of membrane polarity.

Previous studies have noted an increase in Rab25 expression in some ovarian and breast cancers (7). However, other studies have suggested that in estrogen receptor-negative breast cancers, loss of Rab25 actually promotes a more aggressive phenotype (8). We have examined induction of breast cancer and metastases in MMTV- 
A $A P C^{\mathrm{Min} / 4}$; $\frac{\text { Rab25 }}{(1 / 4}$
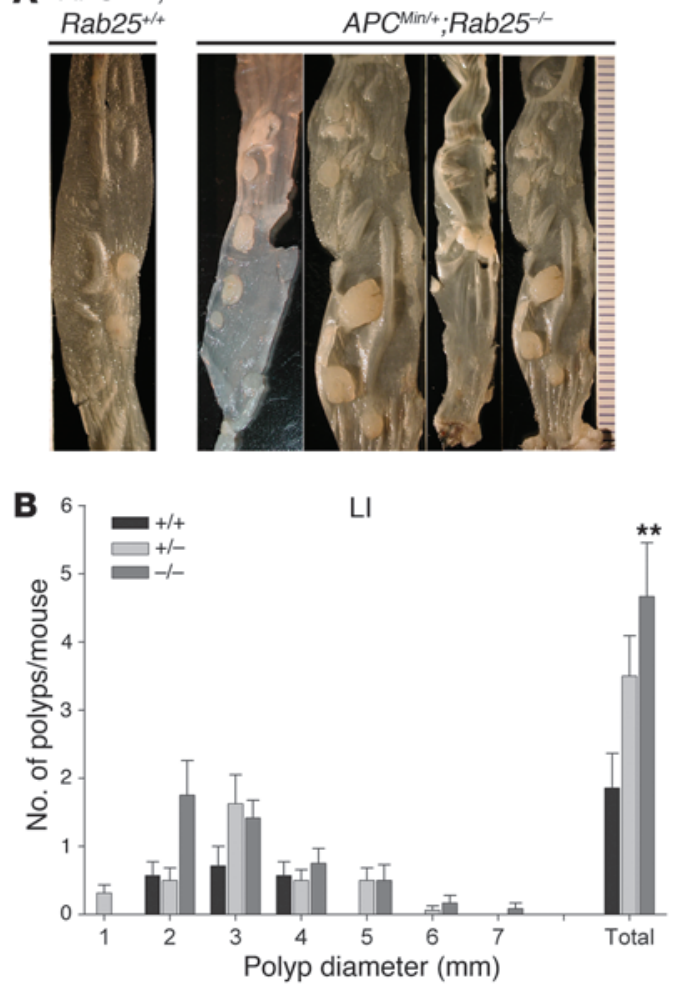

C
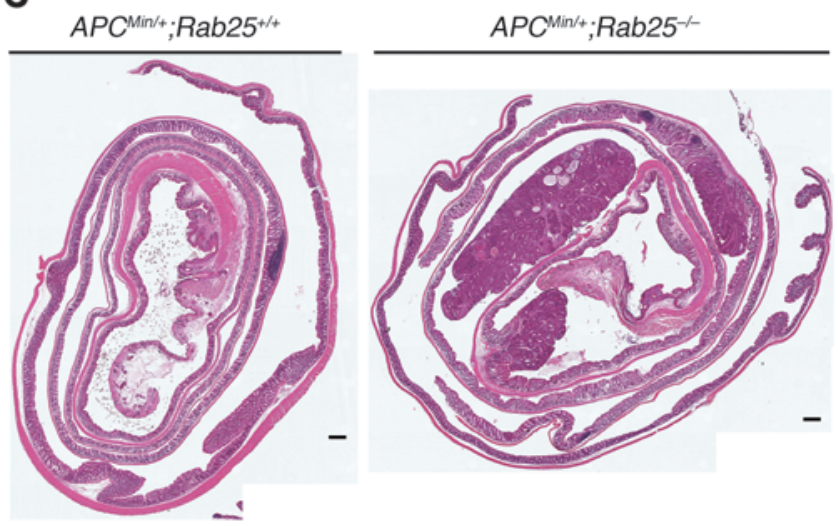

Figure 5

Rab25 deficiency promotes colon adenoma formation in $A p c^{M i n /+}$ mice. (A) Gross appearance of colons from $\mathrm{Apc}^{\mathrm{Min} /+} ; \operatorname{Rab}^{25^{+/+}}(+/+)$and $\mathrm{Apc} \mathrm{Min} /+^{+}$; Rab25 $5^{--}(-/-)$mice. Rab25-deficient mice showed an increase in tumor number as well as an increase in tumor size throughout the colon. (B) The size distribution of polyps in the colons of $A p c^{\mathrm{Min} /+} ; \mathrm{Rab}^{25^{+/+}}(+/+)$ $(n=7), \mathrm{Apc}^{\mathrm{Min} /+} ; \mathrm{Rab}^{25^{+/-}}(+/-)(n=16)$, and $\mathrm{Apc}^{\mathrm{Min} /+} ; \mathrm{Rab}^{25^{-/}}(-/-)$ mice $(n=12)$. Apc ${ }^{\mathrm{Min} /+} ; \mathrm{Rab}^{-1-}$ mice showed a significant increase in colon tumor numbers $\left({ }^{* *} P<0.01\right)$. Data represent mean \pm SEM. (C) Representative Swiss rolls of colon from Apc Min/+;Rab25 $5^{+/+}(+/+)$and $\mathrm{Apc}^{\mathrm{Min} /+} ; \mathrm{Rab}^{25^{-/-}}(-/-)$mice showing the prominent increase in tumor size in the Rab25-deficient mice. Scale bars: $1 \mathrm{~mm}$.

polyoma middle T-expressing mice crossed onto the Rab25-null background and observed no significant effects of Rab25 deficiency on either development of breast tumors or lung metastases (B. Fingleton and J.R. Goldenring, unpublished observations). In contrast, in the present study on intestinal neoplasia, Rab25 deficiency promoted colonic neoplasia in 2 different models of either intestinal polyposis or invasive colon cancer. These results suggest that Rab25 likely influences an early step in intestinal neoplasia. We observed that the major expression of Rab25 in the intestine was in the cells just luminal to the active progenitor cells of the crypt. These are the same cells that are thought to be involved in the development of adenomas in $\mathrm{ApC}^{\mathrm{Min} / \mathrm{+}}$ mice $(24,31)$. It is of interest that we observed decreases in Rab25 expression in these cells in $A p c^{M i n /+}$ mice compared with wild-type mice. Further
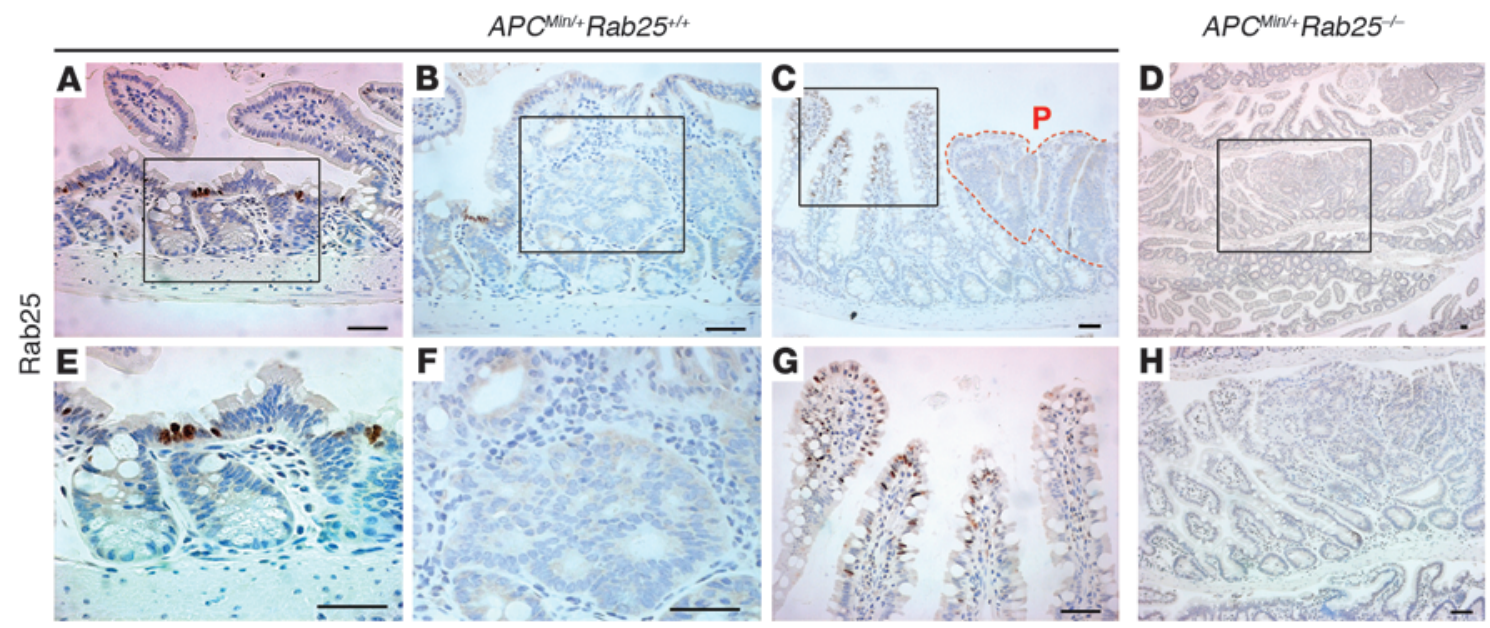

Figure 6

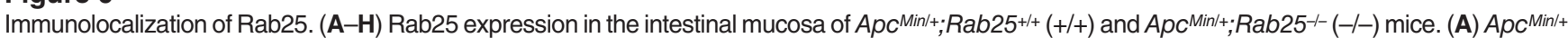
mice with $R a b 25^{++}$background showed decreased Rab25 immunostaining in the cells at the transition from crypt to villus. (B) No Rab25 staining was observed in early adenomas polyp. Rab25-positive cells were still located in the transition zone from crypt to villus in adjacent normal villi. (C) In some nonadenomatous areas, ectopic expression of Rab25 was observed in villus cells adjacent to developed intestinal polyps. P, polyp. (D) No Rab25 staining was found in $\mathrm{Apc}^{\mathrm{Min} /+}$ mice on a Rab25-deficient background. (E-H) Higher magnification views of A-D. Scale bars: $50 \mu \mathrm{m}$. 

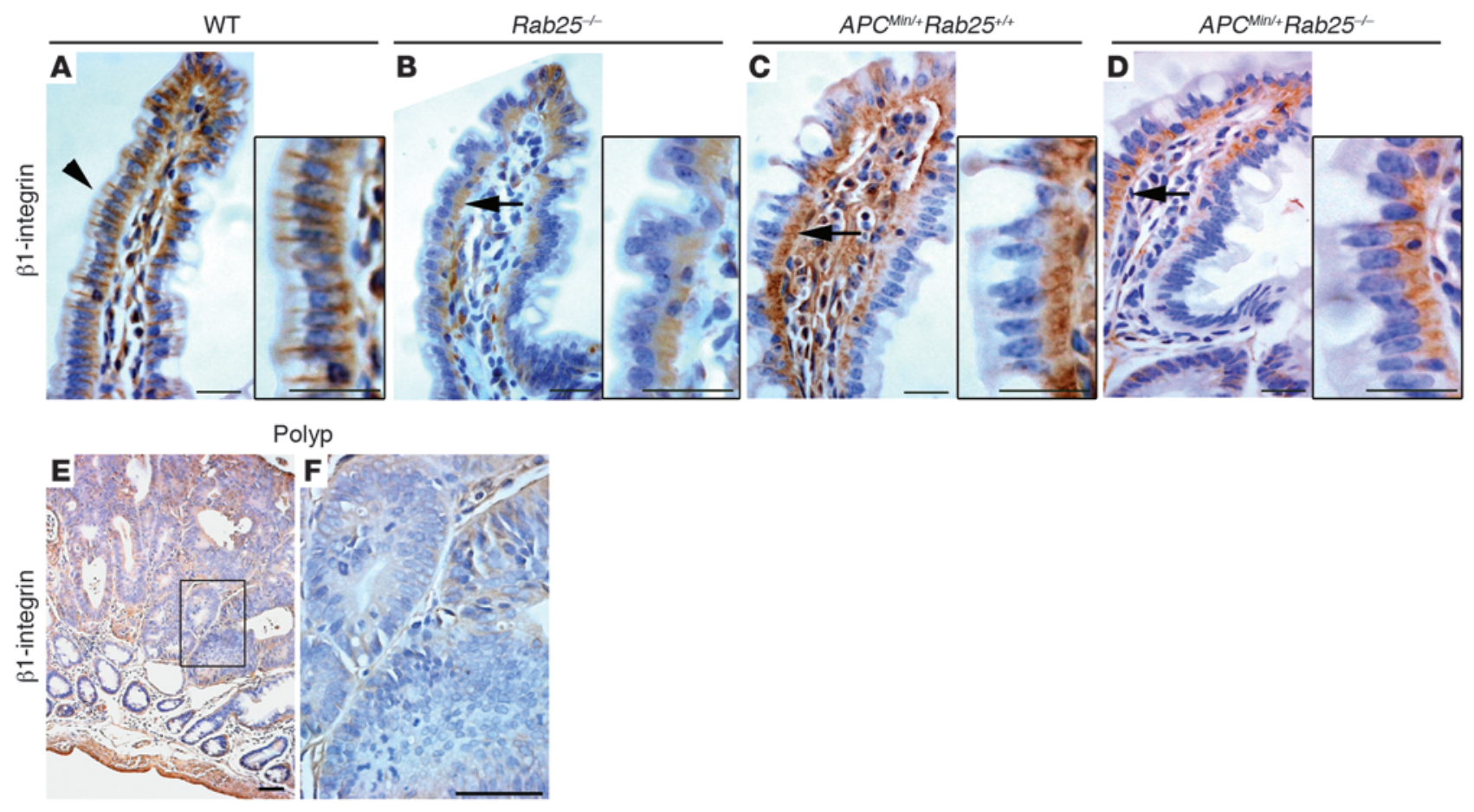

\section{Figure 7}

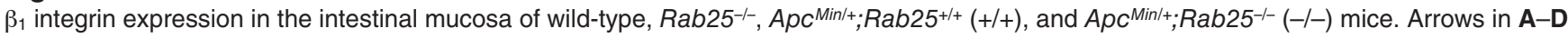
indicate the positions of regions shown at higher magnification. (A) Wild-type mice showed prominent lateral membrane localization of $\beta_{1}$ integrin in villus cells (arrowhead). Scale bars: $25 \mu \mathrm{m}$. (B) Villus cells in Rab25-deficient mice had diminished lateral staining with more prominent intracellular staining for $\beta_{1}$ integrin (arrow). Scale bars: $25 \mu \mathrm{m}$. (C) In Apc Min/+ mice, we noted reduced $\beta_{1}$ integrin staining in the lateral membranes of villus cells (arrow). Scale bars: $25 \mu \mathrm{m}$. (D) In Apc Min/+; Rab25 $5^{-/-}$mice, we observed essentially complete loss of lateral $\beta_{1}$ integrin staining, with

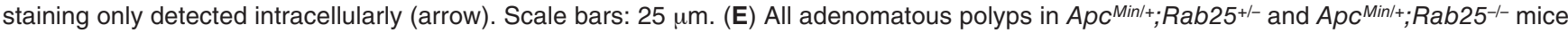
showed a similar marked loss of $\beta_{1}$ integrin staining. Scale bar: $50 \mu \mathrm{m}$. (F) Higher magnification view of E. Scale bar: $50 \mu \mathrm{m}$.

reduction in Rab25 may therefore have led to the acceleration of adenoma formation. This concept is supported by the intermediate effect on $A p c^{M i n /+}$ mouse tumor formation on the haploinsufficient $R a b 25^{+/-}$background. While it is not clear what range of cargoes is affected by the loss of Rab25, we did observe prominent reductions in lateral $\beta_{1}$ integrin in $A p c^{\mathrm{Min} /+}$ mice and Rab25-null mice. Jones et al. (31) have previously demonstrated that loss of $\beta_{1}$ integrin can lead to intestinal hyperplasia. Chaurasia et al. (32) have also demonstrated that alterations in $\alpha_{5} \beta_{1}$ integrin interactions can lead to increases in metastatic behavior. Thus, loss of Rab25 may promote mislocalization of integrin away from the lateral membranes, thus promoting further proneoplastic influences. Given the variety of specific cargoes expressed in different epithelial cells and the previous results in breast cancer cells, it seems likely that either Rab25 loss or Rab25 overexpression could lead to transformation, depending on the particular cargoes trafficked in individual epithelial cell populations.

The data presented here also support a role for Rab25 as an early general colonic tumor suppressor. Rab25 loss also led to a marked acceleration in invasive colon tumor formation in $\mathrm{Smad3^{+/- }}$ mice. The general phenotype of the $S$ mad3 $3^{+-} ; R_{a b 25^{-/-}}$mice was similar to previously reported accelerated pathology in $A \mathrm{pC}^{\mathrm{Min} /+} ; \mathrm{Smad3}^{-/-}$ mice (33). The Apc $\mathrm{Min} /+^{+} ; \mathrm{Smad3}^{-/-}$mice also showed more rapid and extensive colon tumor formation. Those investigations suggested that Wnt and TGF- $\beta$ receptor-mediated pathways could cooper- ate in regulation of tumor suppression. In the case of the studies reported here, we observed marked tumor formation in Smad3 heterozygote mice on the Rab25-deficient background. These results indicate that multiple pathways can synergize to lead to the eventual manifestation of colon tumor formation. It seems logical that disruption of aspects of polarized trafficking through the loss of Rab25 could predispose mucosal epithelial cells to secondary perturbations by either loss of Apc function or loss of Smad3, leading to accelerated transformation.

In summary, the present investigations demonstrate that loss of Rab25 leads to increased tumorigenesis in both $A p c^{\mathrm{Min} /+}$ mice and $\mathrm{Smad3}^{+/-}$mice. Given our findings that lower Rab25 expression is associated with poorer prognosis in colon cancer patients, the present investigations suggest that reduction of Rab25 expression is associated with the initiation of colonic neoplasia. The loss of $\beta_{1}$ integrin staining at the lateral membrane supports a scenario in which loss of Rab25 leads to an alteration in trafficking of key cargoes regulating aspects of polarity, thus predisposing intestinal and colonic epithelial to transformation. All of these findings support a role for Rab25 as an early tumor suppressor in the intestinal mucosa.

\section{Methods}

Construction of Rab25-deficient mice. A 20-kb fragment of the mouse Rab25 gene containing all 5 exons was previously isolated. An EcoRV fragment 

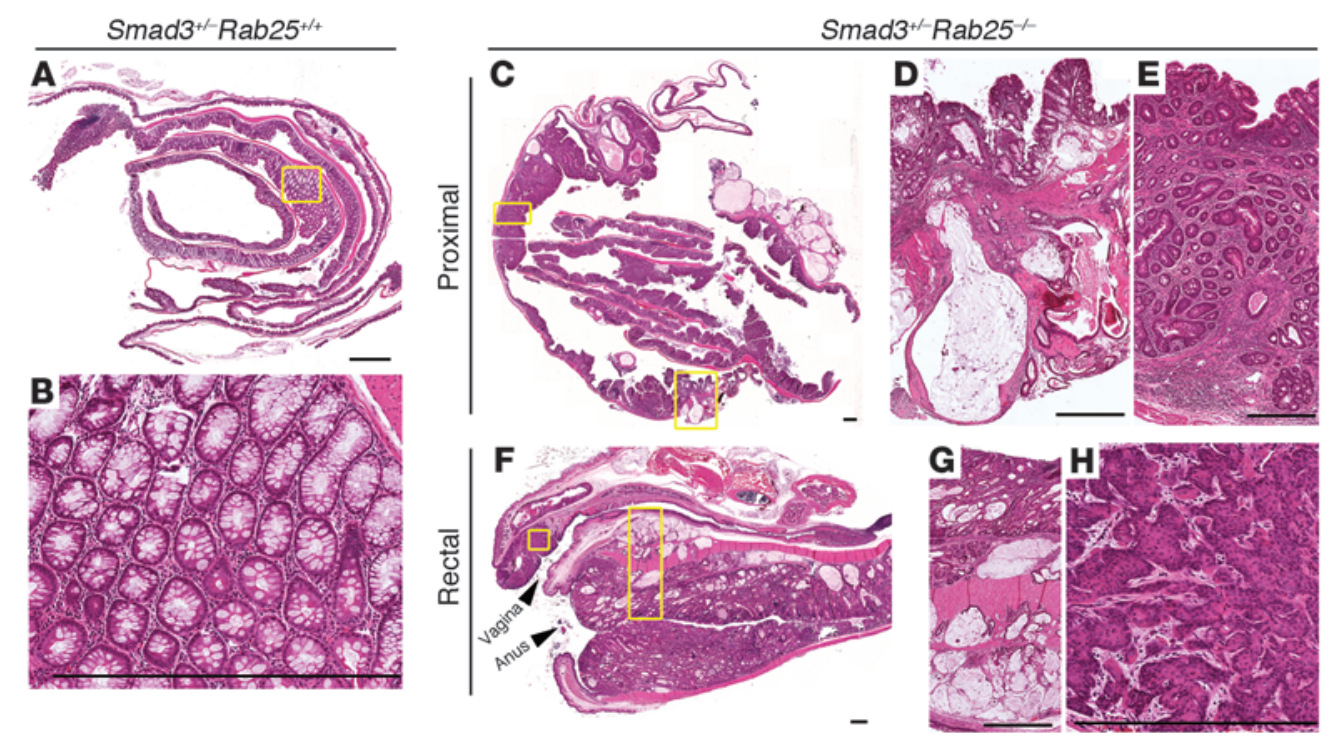

\section{Figure 8}

Rab25 deficiency promotes colon tumor formation and neoplasia in Smad3+/- mice. (A) Smad3 heterozygote mice on a Rab25 wild-type background did not show any adenomas in their colons. (B) Higher magnification of view of $\mathbf{A}$ shows normal colonic mucosa. (C) Swiss roll of Smad3 ${ }^{+--} ; \mathrm{Rab}^{-/-}$mouse colon. Note the numerous mucin-filled cysts. The image was captured using an Ario SL-50 imager. Areas of the image in which no tissue was present appear blank. (D) In a more aggressive proximal tumor, the cancerous lesions penetrated into the serosal wall with neoplastic atypical cystic glands filled with mucin. (E) The neoplastic colonic epithelium invaded into and through the submucosa, and the neoplastic glands invaded the muscle wall. (F) Rectal area of Smad3 $3^{+/ ;}$Rab25-/- mice. The neoplastic colonic epithelium penetrated muscle wall with atypical cystic glands filled with mucin. (G) Atypical cystic glands in epithelium and penetrating the muscle wall. (H) Vagina neoplasia. In vaginal epithelium, neoplastic squamous epithelial cells invaded the muscle layer. The vaginal lesions were not specific to $\mathrm{Apc}^{\mathrm{Min} /+}$ mice and were seen in Rab25-deficient mice on the 129 background. Scale bars: $1 \mathrm{~mm}$.

containing all 5 exons was cloned into pBluescript. The Rab25 gene was interrupted by insertion of the Neomycin resistance gene along with 3 tandem in-frame stop codons into the second exon. The resulting transgene was then linearized and injected into R1 ES cells. Cells were screened for neomycin resistance, and candidate cell lines were examined for homologous recombination by Southern blotting of EcoRV digests of genomic DNA. Two selected cell lines were injected in blastocysts, and chimeras were identified. One founder line was transmitted $100 \%$ to offspring. The founders were crossed through 12 generations to both C57BL/6 mice and $129 / \mathrm{J}$ mice. During the experiments, the mice were maintained with regular mouse chow and water ad libitum in a temperature-controlled room under a 12-hour light/12-hour dark cycle. The care, maintenance, and treatment of animals in these studies followed protocols approved by the Institutional Animal Care and Use Committee of Vanderbilt University.

Southern blotting. Genomic DNA was isolated from mouse tails using a QIAGEN Genomic DNA isolation kit (QIAGEN). $2 \mu \mathrm{g}$ of genomic DNA was digested overnight at $37^{\circ} \mathrm{C}$ with EcoRV. Southern blots were probed with [ $\left.{ }^{32} \mathrm{P}\right]$-labeled DNA probe corresponding to the unique 3 ' coding sequence of murine Rab25.

PCR assay. $1 \mu \mathrm{g}$ of genomic DNA was utilized to amplify wild-type and knockout sequences using a 3-primer reaction. Primer sequences are listed in Supplemental Table 3.

Anti-Rab25 antibody. The rabbit polyclonal antibody was raised against a specific peptide sequence at the murine Rab25 carboxyterminal variable domain, QNSTRTSAITLGNAQAGQDPGLGEKR. KLH was covalently attached to the $\mathrm{N}$ terminus for immunization of the rabbits (Covance). The antiserum was affinity purified against the immunization peptide covalently coupled by the carboxyl terminus to a solid matrix (EDC/Diaminodipropylamine Immobilization kit; Pierce). Rab25 antibodies did not recognize either recombinant Rab11a or Rab11b (L. Lapierre and J.R. Goldenring, unpublished observations). Rab25 antibodies stained discrete populations of epithelial cells, including stomach, esophagus, skin, tongue, and kidney (Supplemental Figure 1) as well as cells within the intestines.

\section{Table 1}

Colon tumor development in Smad3 ${ }^{+/}$mice in the absence of Rab25

\begin{tabular}{|c|c|c|c|c|c|c|c|}
\hline \multirow[t]{2}{*}{ Genotype } & \multirow{2}{*}{$\begin{array}{l}\text { Tumor-bearing } \\
\text { mice }\end{array}$} & \multirow{2}{*}{$\begin{array}{l}\text { Average } \\
\text { tumor no. }\end{array}$} & \multirow{2}{*}{$\begin{array}{c}\text { Adenoma } \\
\text { no. }\end{array}$} & \multicolumn{3}{|c|}{ Depth of tumor invasion } & \multirow{2}{*}{$\begin{array}{l}\text { Rectal } \\
\text { tumor }\end{array}$} \\
\hline & & & & Submucosa & Muscularis & Serosa & \\
\hline $\begin{array}{l}\text {Smad3}^{+/-} ; \mathrm{Rab}^{25^{+/+}} \\
\text {Smad3+/- }^{+1} \text { Rab25 }^{-/-}\end{array}$ & $\begin{array}{l}0 / 10 \\
8 / 10\end{array}$ & $\begin{array}{c}0 \\
5.75 \pm 1.13\end{array}$ & $\begin{array}{c}0 \\
1.34 \pm 0.2\end{array}$ & $\begin{array}{c}0 \\
2.86 \pm 0.59\end{array}$ & $\begin{array}{c}0 \\
2.8 \pm 0.29\end{array}$ & $\begin{array}{c}0 \\
1.25 \pm 0.17\end{array}$ & $\begin{array}{c}0 \\
1.0 \pm 0.0\end{array}$ \\
\hline
\end{tabular}

Quantitation of tumor development in $S m a d 3^{+/-}$mice. For tumor-bearing mice, the average numbers of tumors per colon and adenomas per colon were determined $( \pm$ SEM). In addition, we assessed the number of tumors per mouse that invaded the submucosa, muscularis mucosa, or the serosa. Finally, we assessed the number of rectal tumors present per mouse. No tumors were observed in Smad3 $3^{+/-}$mice on a wild-type Rab25 background. 


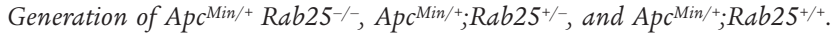
$\mathrm{C} 57 \mathrm{BL} / 6 \mathrm{~J}-A p c^{\mathrm{Min} /+}$ mice were obtained from The Jackson Laboratory. $A p c^{\mathrm{Min} /+}$ males were mated with C57BL/6 background Rab25/- females to generate $\mathrm{Apc} \mathrm{Min} /+^{-}$Rab25 $5^{+/-}$mice. Such males were backcrossed with Rab25-/-

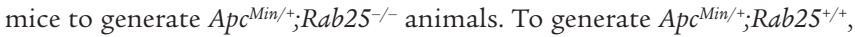
male $A p c^{M i n /+}$ mice were mated with wild-type female mice. The genotype of the offspring for $A p c^{\mathrm{Min} /+}$ was analyzed by a PCR assay method (Supplemental Table 3). All of the mice were killed at the age of 15 weeks.

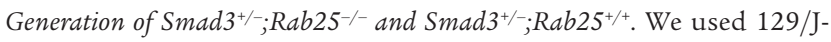
$\mathrm{Smad3}^{+/-}$mice. Smad3 $3^{+/-}$males were mated with 129/J background Rab25-/-

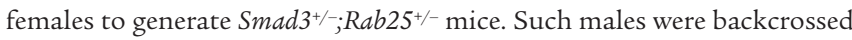
with $\mathrm{Rab}_{25^{-/}}$mice to generate $S$ mad3 $3^{+/-} ; \mathrm{Rab}^{25^{-/-}}$animals. The genotype of the offspring for $\mathrm{Smad3}^{+/-}$was analyzed by a PCR assay method (Supplemental Table 3). All of the mice were killed at the age of 10 months.

Polyp number scoring and histopathology. Immediately after sacrifice, both ends of the small and large intestines were tied with thread, and the guts were inflated with $10 \%$ phosphate-buffered formalin. After 24 hours, they were opened longitudinally to wash the formalin and luminal contents from the mucosal surface. The numbers and the major diameters of the polyps in small and large bowels were measured per $\times 10$ power field of a stereoscopic microscope. For histological examination, formalin-fixed intestines were prepared by the Swiss roll method and embedded in paraffin, and $5-\mu \mathrm{m}$ sections were prepared for $\mathrm{H} \& \mathrm{E}$ staining and immunohistochemistry.

Analysis of human-expression profiling. Gene expression data from Kaiser et al. (21) was analyzed using Robust MultiChip Averaging (RMA) normalized values from a series of 100 carefully dissected colorectal cancer isolates that were compared with 5 normal colonic mucosal samples. These samples were collected with informed subject consent and analyzed under a protocol approved by the Institutional Review Board of the Moffitt Cancer Center. Probe sets and corresponding gene transcripts whose expression was highly correlated to that of RAB25 were identified in the human data set using Pearson correlation to the high-quality probe set for human RAB25, 218186_at, as measured versus all probe sets with gene expression greater than an RMA of 6.0 in more than 4 samples. This generated a list of 530 correlated probe sets. Enrichment analysis for overrepresented geneassociated features including known protein interactions, pathways, and shared gene ontology relationships was performed using ToppGene (34).

The protocols and procedures for the Vanderbilt Medical Center (VMC) cohort were approved by the Institutional Review Boards at the University of Alabama-Birmingham Medical Center (Birmingham, AL, USA), Vanderbilt Medical Center, and the Veterans Administration Hospital (Nashville, TN). Representative sections of fresh tissue specimens were flash frozen in liquid nitrogen and stored at $-80^{\circ} \mathrm{C}$ until RNA isolation. Quality assessment slides were obtained to verify the diagnosis. Stage was assessed by American Joint Commission on Cancer (AJCC) guidelines for the tumor samples. RNA was purified using the RNeasy kit (QIAGEN). Human samples were hybridized to the Human Genome U133 Plus 2.0 GeneChip Expression Affymetrix array. Microarray data were normalized using the RMA algorithm (35) as implemented in the Bioconductor package Affy. For pairwise group comparisons, $t$ test in the Limma package (36) in Bioconductor was used to identify differentially expressed probe sets between the 2 groups under comparison. The implementation of $t$ test in Limma uses an empirical Bayes method to moderate the standard errors of the estimated log fold changes; this results in a more stable inference, especially for experiments with a small number of arrays.

$R N A$ collection for quantitative RT-PCR. Four normal colon samples were taken from patients with diverticulitis, and 10 colon adenocarcinoma samples were obtained at VMC. The patient samples used for this analysis were independent of the 61 samples used for the adenoma-to-carcinoma comparison. All adenocarcinoma patients for the qPCR work were staged by AJCC criteria. All protocols and procedures were approved by the Vanderbilt Institutional Review Board. Criteria for use of normal or tumor samples was greater than $80 \%$ contribution of normal mucosa or tumor on the $\mathrm{H} \& \mathrm{E}$ slides used to determine potential for RNA isolation. Once normal mucosa or tumor was verified, RNA was collected from fresh frozen tissue with the QIAGEN RNeasy kit. Samples were DNAse treated on column (QIAGEN) during purification and eluted with $50 \mu \mathrm{l}$ RNAse/DNAsefree water. RNA integrity was determined on an Agilent Bioanalyzer (Agilent Technologies Inc.). Samples with RNA integrity numbers suitable for hybridization for microarray analysis (RNA integrity > 6.2) were used.

Quantitative RT-PCR. RNA (300 ng) was reverse transcribed using oligo$\mathrm{dT}$ primers and SuperScript III (Invitrogen) reverse transcriptase. $20 \mu \mathrm{l}$ reactions were incubated for 30 minutes at $50^{\circ} \mathrm{C}$ followed by 5 minutes at $95^{\circ} \mathrm{C}$ to inactivate enzyme. All cDNAs were diluted with $80 \mu$ l of nucleasefree water. PCR reactions were performed using gene-specific primers for Rab25 and PMM1 as a control (PMM1 sense: 5'-CTCCTAGTGGCACTGGCTTC-3' and PMM1 antisense: 5'-GCAGGCTAGATCTCGTACCG-3'; Rab25 sense: 5'-TCGCTGAAAACAATGGACTGCTCTT-3' and Rab25 antisense: 5'- ATTGGTCCGGATGCTGTTCTGTCTCT-3'). Each well contained SYBR Green Master Mix from SuperArray combined with primer sets $(10 \mu \mathrm{M})$ and $1 \mu \mathrm{l}$ of cDNA prepared and used on the same day for the PCR reactions. Each cDNA reaction was loaded in quadruplicate in 96-well plates and run on a Bio-Rad iCycler under the following protocol (1: $95^{\circ} \mathrm{C}, 30$ seconds; 2 : $95^{\circ} \mathrm{C}, 30$ seconds; $3: 95^{\circ} \mathrm{C}, 13$ minutes- 30 seconds; $4: 95^{\circ} \mathrm{C}, 15$ seconds; $55^{\circ} \mathrm{C}, 30$ seconds; $72^{\circ} \mathrm{C}, 30$ seconds ( 45 cycles); 5: $72^{\circ} \mathrm{C}, 7$ minutes; $6: 55^{\circ} \mathrm{C}, 10$ minutes).

For each individual well, fluorescence curves were log transformed, and the slope of the logarithmic portion of the reaction was extracted to determine efficiency. Ct values and efficiency were then utilized to calculate fold change (37). Normalization was done with PMM1 (38). Efficiency-adjusted $\mathrm{Ct}$ values were determined for normal and tumor samples. Ct values for each normal and for each tumor sample were determined compared with a normal or tumor reference $\mathrm{Ct}$ value, and $1 / \mathrm{Ct}$ was then displayed. Significant differences were determined using a nonparametric Mann-Whitney $U$ test.

Immunohistochemistry. We carried out immunohistochemistry according to the manufacturer's recommendations, typically using a modified citric acid unmasking protocol followed by standard detection with 3,3'-diaminobenzidine (DAB) using a kit from Vector Laboratories. Samples were counter-stained with hematoxylin. In some cases, secondary antibodies were conjugated to Alexa Fluor 488 (Invitrogen), and nuclei were counterstained with DAPI. We used the following primary antibodies: rabbit anti-rab25 (1:20) and rat anti- $\beta_{1}$ integrin (1:100; Chemicon).

Loss of heterozygosity analysis and laser capture microdissection. In the current study, the DNA for the analysis of the Apc allelic loss was extracted from the cells isolated with laser microdissected tissue sections as described previously (26). Microdissection was done using a laser microdissection system (Molecular Devices). The microdissected tissues of tumors from $A p c^{\mathrm{Min} /+} ; \mathrm{Rab}_{25^{+/+}}$and $\mathrm{ApC} \mathrm{Min} /+^{-+}$Rab $25^{-/-}$mice were used for the analysis. Genomic DNA was extracted and isolated using PicoPure DNA Isolation Kit (Molecular Devices) immediately following collection of tissues. Loss of heterozygosity (LOH) of the Apc gene was assessed using PCR with mismatched primers as described previously (25).

Statistics. The data were analyzed with the JMP software package (version 4.0; SAS Institute). Polyp numbers were compared with analysis of variance followed by post hoc analysis of significant means by Dunnett's test. For all comparisons, $P$ values less than 0.05 were considered statistically significant.

\section{Acknowledgments}

This work was supported by NIH grants RO1 DK48370 and R21 AR49311 and a VA Merit Review award (to J.R. Goldenring); an 
American Cancer Society Institutional Research grant (IRG-58009-48) and the Sartain-Lanier Family Foundation (to L.A. Lapierre); the Cincinnati Digestive Health Center (PHS grant P30 DK078392), NCI UO1 CA84291-07 (Mouse Models of Human Cancer) (to B. Aronow); NCI CA46413, GI Special Program of Research Excellence (P50 CA95103), Mouse Models of Human Cancers Consortium (U01 CA084239) to R.J. Coffey; CA69457, DK52334, CA068485, and CA077839 to R.D. Beauchamp; and CA112215 to T.J. Yeatman. J.J. Smith was supported by T32 CA106183 and a Society of University Surgeons-Ethicon Scholarship Award. This work was supported by core resources of the Vanderbilt Digestive Disease Center, P30 DK058404, and the Vanderbilt-Ingram Comprehensive Cancer Center. We would like to thank the staff of the Medical College of Georgia Transgenic/Knockout Mouse core for their assistance in developing the Rab25-deficient mouse. We would like to thank Jeff Franklin for critical review of this manuscript and John Neff for assistance with nude mice.

Received for publication August 6, 2009, and accepted in revised form December 16, 2009.

Address correspondence to: James R. Goldenring, Vanderbilt University School of Medicine, Department of Surgery, Epithelial Biology Center, 10435G MRBIV, 2213 Garland Avenue, Nashville, TN 37232-2733, USA. Phone: 615.936.3726; Fax: 615.343.1591; E-mail: jim.goldenring@vanderbilt.edu.
1. Juliano RL. Signal transduction by cell adhesion receptors and the cytoskeleton: functions of integrins, cadherins, selectins, and immunoglobulinsuperfamily members. Annu Rev Pharmacol Toxicol. 2002;42:283-323.

2. Mosesson Y, Mills GB, Yarden Y. Derailed endocytosis: an emerging feature of cancer. Nat Rev Cancer. 2008;8(11):835-850.

3. Novick P, Zerial M. The diversity of Rab proteins in vesicle transport. Curr Opin Cell Biol. 1997; 9(4):496-504.

4. Schwartz SL, Cao C, Pylypenko O, Rak A, Wandinger-Ness A. Rab GTPases at a glance. J Cell Sci. 2007;120(Pt 22):3905-3910.

5. Goldenring JR, Shen KR, Vaughan HD, Modlin IM. Identification of a small GTP-binding protein, Rab25, expressed in the gastrointestinal mucosa, kidney, and lung. J Biol Chem. 1993;268(25):18419-18422.

6. Lapierre LA, et al. Myosin vb is associated with plasma membrane recycling systems. Mol Biol Cell. 2001;12(6):1843-1857.

7. Cheng KW, et al. The RAB25 small GTPase determines aggressiveness of ovarian and breast cancers. Nat Med. 2004;10(11):1251-1256.

8. Cheng JM, Ding M, Aribi A, Shah P, Rao K. Loss of RAB25 expression in breast cancer. Int J Cancer. 2006;118(12):2957-2964.

9. Caswell PT, et al. Rab25 associates with alpha5beta1 integrin to promote invasive migration in $3 \mathrm{D}$ microenvironments. Dev Cell. 2007;13(4):496-510.

10. Kinzler KW, Vogelstein B. Lessons from hereditary colorectal cancer. Cell. 1996;87(2):159-170.

11. Boivin GP, et al. Pathology of mouse models of intestinal cancer: consensus report and recommendations. Gastroenterology. 2003;124(3):762-777.

12. Groden J, et al. Identification and characterization of the familial adenomatous polyposis coli gene. Cell. 1991;66(3):589-600.

13. Kinzler KW, et al. Identification of a gene located at chromosome $5 \mathrm{q} 21$ that is mutated in colorectal cancers. Science. 1991;251(4999):1366-1370.

14. Moser AR, Pitot HC, Dove WF. A dominant mutation that predisposes to multiple intestinal neoplasia in the mouse. Science. 1990;247(4940):322-324.

15. Su LK, et al. Multiple intestinal neoplasia caused by a mutation in the murine homolog of the APC gene. Science. 1992;256(5057):668-670.

16. Takaku K, Oshima M, Miyoshi H, Matsui M, Seldin MF, Taketo MM. Intestinal tumorigenesis in compound mutant mice of both Dpc4 (Smad4) and Apc genes. Cell. 1998;92(5):645-656.

17. Engle SJ, Hoying JB, Boivin GP, Ormsby I, Gartside PS, Doetschman T. Transforming growth factor beta1 suppresses nonmetastatic colon cancer at an early stage of tumorigenesis. Cancer Res. 1999;59(14):3379-3386.

18. Bronner CE, et al. Mutation in the DNA mismatch repair gene homologue hMLH1 is associated with hereditary non-polyposis colon cancer. Nature. 1994;368(6468):258-261.

19. Markowitz S, et al. Inactivation of the type II TGFbeta receptor in colon cancer cells with microsatellite instability. Science. 1995;268(5215):1336-1338.

20. Zhu Y, Richardson JA, Parada LF, Graff JM. Smad3 mutant mice develop metastatic colorectal cancer. Cell. 1998;94(6):703-714.

21. Kaiser S, et al. Transcriptional recapitulation and subversion of embryonic colon development by mouse colon tumor models and human colon cancer. Genome Biol. 2007;8(7):R131.

22. Smith JJ, et al. An experimentally derived metastasis gene expression profile predicts cancer-related recurrence and death in colon cancer patients [published online ahead of print November 16, 2009]. Gastroenterology. doi:10.1053/j.gastro.2009.11.005.

23. Ray GS, Lee JR, Nwokeji K, Mills LR, Goldenring JR. Increased immunoreactivity for Rab11, a small GTP-binding protein, in low-grade dysplastic Barrett's epithelia. Lab Invest. 1997;77(5):503-511.

24. Oshima H, Oshima M, Kobayashi M, Tsutsumi M, Taketo MM. Morphological and molecular processes of polyp formation in Apc(delta716) knockout mice. Cancer Res. 1997;57(9):1644-1649.

25. Luongo C, Moser AR, Gledhill S, Dove WF. Loss of $\mathrm{Apc}^{+}$in intestinal adenomas from Min mice. Cancer Res. 1994;54(22):5947-5952.

26. Yamada Y, et al. Microadenomatous lesions involving loss of Apc heterozygosity in the colon of adult $\mathrm{Apc}(\mathrm{Min} /+)$ mice. Cancer Res. 2002; 62(22):6367-6370.

27. Ducharme NA, et al. MARK2/EMK1/Par-1Balpha phosphorylation of Rab11-family interacting pro- tein 2 is necessary for the timely establishment of polarity in Madin-Darby canine kidney cells. Mol Biol Cell. 2006;17(8):3625-3637.

28. Behrens J, et al. Loss of epithelial differentiation and gain of invasiveness correlates with tyrosine phosphorylation of the E-cadherin/beta-catenin complex in cells transformed with a temperature-sensitive v-SRC gene. J Cell Biol. 1993;120(3):757-766.

29. Hales CM, et al. Identification and characterization of a family of Rab11-interacting proteins. J Biol Chem. 2001;276(42):39067-39075.

30. Wang X, Kumar R, Navarre J, Casanova JE, Goldenring JR. Regulation of vesicle trafficking in MadinDarby Canine Kidney cells by Rab11a and Rab25. J Biol Chem. 2000;275(37):29138-29146.

31. Jones RG, et al. Conditional deletion of beta1 integrins in the intestinal epithelium causes a loss of Hedgehog expression, intestinal hyperplasia, and early postnatal lethality.J Cell Biol. 2006;175(3):505-514.

32. Chaurasia P, Mezei M, Zhou MM, Ossowski L. Computer aided identification of small molecules disrupting uPAR/alpha5beta1-integrin interaction: a new paradigm for metastasis prevention. PLoS ONE. 2009;4(2):e4617.

33. Sodir NM, et al. Smad3 deficiency promotes tumorigenesis in the distal colon of ApcMin/+ mice. Cancer Res. 2006;66(17):8430-8438.

34. Chen J, Xu H, Aronow BJ, Jegga AG. Improved human disease candidate gene prioritization using mouse phenotype. BMC Bioinformatics. 2007;8:392.

35. Irizarry RA, et al. Exploration, normalization, and summaries of high density oligonucleotide array probe level data. Biostatistics. 2003;4(2):249-264.

36. Smyth GK. Linear models and empirical bayes methods for assessing differential expression in microarray experiments. Stat Appl Genet Mol Biol. 2004;3(1):Article3. doi:10.2202/1544-6115.1027.

37. Schefe JH, Lehmann KE, Buschmann IR, Unger T, Funke-Kaiser H. Quantitative real-time RT-PCR data analysis: current concepts and the novel "gene expression's CT difference" formula. J Mol Med. 2006;84(11):901-910.

38. Rubie C, et al. Housekeeping gene variability in normal and cancerous colorectal, pancreatic, esophageal, gastric and hepatic tissues. Mol Cell Probes. 2005;19(2):101-109. 